Culture \& History Digital Journal 7(1)

June 2018, e003

eISSN 2253-797X

https://doi.org/10.3989/chdj.2018.003

\title{
Aislar para convertir: los presos y sus familias en el primer franquismo
}

\author{
Gutmaro Gómez Bravo

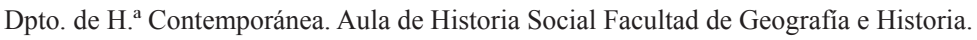 \\ Universidad Complutense de Madrid. Avda Profesor Aranguren S/N 28040, Madrid. \\ e-mail: ggomezb@ucm.es \\ ORCID iD: http://orcid.org/0000-0003-2033-7922
}

Recibido: 8 de enero de 2017. Aceptado: 7 de mayo de 2017

\begin{abstract}
RESUMEN: Las páginas que siguen, fruto de un proyecto de investigación más amplio, giran en torno al tratamiento que recibieron los presos políticos y sus familias, los vencidos y excluidos del franquismo. Un proceso, una puerta principal al mundo del encierro y del control social de postguerra, cuyo significado e intensidad fue variando a lo largo del tiempo. Por ello, es necesario exponer previamente cómo se formó el sistema penitenciario de la postguerra española, en qué consistió la redención de penas, cómo y con qué objetivos concretos se diseñó, en un marcado contexto de masificación y progresiva degradación como el de las prisiones de los años $40 .^{1}$
\end{abstract}

PALABRAS CLAVE: Posguerra; Franquismo; Política penitenciaria; Control social.

Cómo citar este artículo / Citation: Gómez Bravo, Gutmaro (2018) «Aislar para convertir: los presos y sus familias en el primer franquismo». Culture \& History Digital Journal, 7 (1): e003. https://doi.org/10.3989/chdj.2018.003

\begin{abstract}
Isolation and reeducation at Francoism penitentary system.- The following pages, as a result of a wider investigation into political prisoners and their families excluded the defeated Franco. Therefore, it is necessary to show how the penitentiary system postwar is formed, what it consisted of the redemption penalties, how and with what specific objectives are designed in a distinct context of massification and progressive degradation as it was in Spanish prisons after the civil war.
\end{abstract}

KEYWORDS: Spanish postwar; Francoism; Penal policy; Prisons; Social control.

Copyright: ( 2018 CSIC. Este es un artículo de acceso abierto distribuido bajo los términos de la licencia de uso y distribución Creative Commons Reconocimiento 4.0 Internacional (CC BY 4.0).

Las cárceles de posguerra fueron el escenario de un plan diseñado para conseguir el aislamiento de los presos políticos y el control social de sus familias: la redención de penas por el trabajo. De este modo, principalmente, el sistema penitenciario jugó un papel en la institucionalización del franquismo y constituyó durante toda la dictadura, si bien aquí sólo se pueda examinar su primera fase, uno de sus principales y más activos agentes en la criminalización, exclusión y represión de la denominada «población desafecta». Un año antes de que la guerra terminara, el tratamiento de los reclusos estaba ya integrado dentro de un proyecto más amplio de «conversión» de los vencidos, destinado a la recristianización de España (Ál- varez Bolado, 1995; Gómez Bravo, 2009, 2017). La fase más dura de la represión, en plena autarquía, con un estado de excepción latente hasta 1948 y la justicia militar en pleno auge durante toda la década, se presentaba legitimada bajo el mensaje del perdón y la justicia social cristianas. Un cambio de imagen de la política penal vital para una dictadura aislada y acosada internacionalmente tras el fin de la Segunda Guerra Mundial (Casanova, 2017: 25-36; Sierra Blas, 2016). El Estado cedió a la Iglesia paulatinamente desde 1938, todo lo relativo a la reeducación de los presos. El problema es que tuvo que hacerse cargo del mayor número de reclusos alcanzado jamás en la historia de España, 200.000 a mediados de 
ese año, y medio millón apenas un año después, una de las cifras más altas jamás alcanzada en toda Europa occidental (Egido y Eiroa, 2005; Gómez Bravo y Marco, 2012).

La decisión de tratar a los prisioneros de guerra como presos comunes y de involucrar a sus familias en la operación de «regeneración moral de los vencidos» marcaría la configuración inicial de la sociedad de posguerra. La Iglesia española, conmocionada por la guerra y la persecución religiosa, relanzaba el redentorismo como doctrina penal contraria a la humanización de las penas para los hombres, al tiempo que mantenía el correccionalismo cristiano, que había inspirado el sistema penitenciario español desde el siglo XIX, como base del tratamiento a las mujeres delincuentes. La historiografía ha avanzado de manera significativa en el conocimiento de las cifras y las magnitudes de este fenómeno, pero siguen siendo muy escasos los balances o interpretaciones, que desde el rigor y las propias fuentes, traten de analizar las principales consecuencias sociales de la aplicación de este programa. Así, el grado de interiorizaron que los propios presos hicieron de una política como la de la redención de penas, diseñada como el principal vehículo de su reeducación, sigue siendo una incógnita. Para las memorias oficiales y la propaganda franquista fue todo un éxito. Para las víctimas supuso todo lo contrario. En medio de aquella enorme tragedia que había dejado suspendida sus propias vidas, en mitad de aquella incertidumbre, es posible advertir que la mayor angustia y presión psicológica quedaba establecida en la relación entre los presos y sus familias, precisamente el núcleo de la redención de penas por el trabajo. Las páginas que siguen, no tratan de contrastar dos discursos enfrentados por razones obvias, sino más bien contribuir al debate sobre el grado de consecución de los objetivos de aquel tratamiento penal de los años 40, con particular interés en el caso de las presas donde cada vez aparece más evidente la distancia entre los discursos y las prácticas penitenciarias habituales. Por todo ello, es necesario exponer previamente en qué consistió la redención de penas, cómo y con qué objetivos concretos se diseñó, dentro del contexto generalizado de masificación y progresiva degradación como el de las prisiones españolas de los años 40

\section{LA OBRA DE PACIFICACIÓN ESPIRITUAL}

La redención de penas fue concebida como una respuesta a la guerra, pero la mayor parte de sus elementos eran anteriores a ella. Una gran parte de las experiencias puestas en marcha por la Iglesia para frenar la expansión de la secularización en España durante los años 30, fueron continuadas en la postguerra y muy particularmente en ámbitos «difíciles» como las prisiones. Pero no se volvió a enlazar directamente con ellas. La guerra y la persecución religiosa crearon un abismo insalvable que derivó en el intento de eliminación de las bases del anticlericalismo. De este modo, los distintos frentes iniciados para la movilización católica moderna prevista por Pío XI se re- hacen en España al término de la guerra, pero en su versión más integrista (Montero 2007: 71-95). El modelo doctrinal más influyente fue la encíclica Divinis Redemptoris, de 19 de marzo de 1937, sobre el comunismo ateo, que debía ser combatido y, una vez vencido, ser desplazado por la Doctrina Social de la Iglesia. Para ello era necesario recristianizar, abolir la labor secularizadora y devolver a la Iglesia a un lugar preeminente en el espacio público. En España, dicha tarea pasaba por frenar la creciente influencia de Falange tras el Decreto de unificación del Movimiento.

El atributo esencial del nuevo sistema penitenciario español partía, por tanto, de la doctrina tradicional de la Iglesia que llamaba a los católicos «a defenderse» y a colaborar con los poderes terrenales. Las dos ciudades, los dos poderes, como expresó nítidamente el Obispo de Salamanca Pla i Deniel en su pastoral El triunfo de la ciudad de Dios y la resurrección de España de 25 de mayo de 1939, donde la sociedad perfecta (la Iglesia) redime a la imperfecta:

Las masas extraviadas necesitan una rigurosa asepsia de doctrinas corruptoras y la disciplina del orden; que les haga partícipes de los beneficios de una justicia social; que se les reconquiste con efusiones de amor, de amor a los ministros de Cristo» (Pla i Deniel, 1939:23)

La Iglesia interpretó la guerra desde este prisma, e igualmente concibió su misión en la paz. La violencia y agresividad de la guerra se canalizaron por distintas vías en la posguerra, que mantienen la exigencia del castigo. La redención aparece como la fórmula capaz de hacer compatible la caridad con la Justicia, «la base para escapar de los deseos de venganza provocados por los horrores de la guerra (Perez del Pulgar, 1939: 13). El autor de estas palabras y creador del plan de redención de penas, el jesuita Pérez del Pulgar, fue designado a comienzos de 1938 como alto representante de la Iglesia para todas las cuestiones penitenciarias. Una privilegiada posición en la gestión del entramado institucional de Justicia que consiguió delimitar claramente la Iglesia a lo largo de ese año, que difícilmente se hubiera conseguido sin la posición clave de tres ministros del primer gobierno de Franco, miembros todos ellos de la ACNP. El primero de ellos fue el conde de Rodezno, Ministro de Justicia, carlista pero también propagandista católico. Mariano Puigdollers, Director General de Asuntos Eclesiásticos del Ministerio de Justicia y por último, Máximo Cuervo Radigales, Director General de Prisiones entre 1938 y 1942, auditor y militar que había publicado junto a Martín Artajo los comentarios a Doctrina Social Cristiana. A comienzos de 1939, Del Pulgar presentaba la redención como piedra angular del castigo. Durante la guerra había sido necesario «operar lo dañado para salvar lo sano» pero para poder cumplir con el mandato de la Justicia (militar) y la Caridad (cristiana) una vez llegada la paz, era preciso introducir en las penas elementos de retribución del delincuente hacia sus principales víctimas: Dios y España. Para resarcir a la Patria, el elemento clave fue el trabajo. 
A mediados de 1937 ya aparece el primer conjunto de normas encaminando la pena hacia los trabajos forzados. En cuanto a la ofensa a Dios, sólo se podía restablecer el daño producido a través de la penitencia. En esencia, el reo cargaba con su culpa y sólo la Iglesia, «vicaria de Dios en la Tierra», podía ser testigo de su arrepentimiento. Y esta fue la función esencial de los capellanes, certificar el arrepentimiento de los presos.

El programa de Pérez del Pulgar para los capellanes de prisiones se basaba en la estricta observancia de las fases del proceso de penitencia: primero, identificación y reconocimiento de los pecados, en segundo lugar, plegaria de conversión y, por último, enmienda y proyecto de nueva vida. Por lo demás, prescribía a través de la confesión, un conocimiento individual del reo y de sus condiciones familiares. Familia, trabajo, vida honesta y ocio saludable. Se trataba de la Doctrina Social Cristiana, que en este momento señalaban las coordenadas del proyecto de estado corporativo español en el que también se fundía el «derecho al trabajo» falangista. ${ }^{2}$ La combinación de principios religiosos, políticos y sociales terminó engendrando una clara línea divisoria entre el trabajo, la alfabetización y la propaganda, que quedó sancionada legalmente el 23 de noviembre de 1940 mediante el decreto que «concedía el beneficio de la redención de penas a los condenados que durante su estancia en prisión lograsen instrucción religiosa o cultural». Así, el tercer pilar de la propaganda, después de la enseñanza religiosa y la patriótica, fue la denominada cultural y artística, basada en la utilización de artistas e intelectuales en prisión. El propagandista católico clave en este frente fue José María Sánchez de Muniain; adaptó el mensaje de la redención a la vida en prisiones, reforzando la idea y el método de conversión a través de la especialización y el aislamiento individual. La consolidación de las prisiones de los años 40 no puede entenderse sin este anhelo de mostrar a los intelectuales arrepentidos y a los obreros convertidos trabajando para el régimen. Para ello creó Redención, «el periódico de los presos y sus familias», que Muniain destacaba como «un arte generativo de amor al contrario» (Sánchez de Muniain, 1946: 205-246).

Todos estos principios resultaban, sin embargo, demasiado elevados para la inmensa mayoría de los presos. La versión más popular para propagar estas ideas fue difundida por el capellán de la cárcel Modelo de Barcelona, el padre Martín Torrent, a través de un librito titulado ¿Qué me dice usted de los presos?, que repetía básicamente las ideas de Del Pulgar pero en estilo coloquial. Siendo ya el Capellán Mayor de Prisiones, en 1946, pasó revista a aquellos primeros años de posguerra y a su objetivo principal: conocerlos, separarlos y clasificarlos en grupos. Como recordaba Torrent años después, se trataba de ordenar la masa e individualizarlos: «unos, dispuestos a recibir de buen grado y voluntad la semilla evangelizadora; otros, remisos, de fe perdida o ignorada; otros, incrédulos por ignorancia o rencor, y otros, en fin, materialistas fundamentales dispuestos a la oposición y a la negación terminante de la posibilidad espiritual» (Martin Torrent, 1946: 23-34). Estos principios de individualización, que había expuesto Del Pulgar siguiendo la máxima papal de justicia con el crimen y benevolencia con el engañado en plena guerra, inspiraron los reglamentos penitenciarios de 1948 y 1956, que mantenían las técnicas de modificación de la conducta basados en categorías de conversión religiosa, en el aislamiento para romper la fuerte solidaridad de los colectivos políticos en prisión y, por último, en vincular el destino del preso al de su familia.

El punto culminante de este plan de reeducación era conseguir que el preso volviera a la sociedad transformado en un cristiano, en un español y en un trabajador perfecto. Para ello, en enero de 1939, la redención de penas ya estaba legalmente vinculada a la libertad condicional. Nadie saldría de la cárcel sin haber pasado por una de sus fases, y, lo que fue más importante para la consecución del ideal de paz social franquista, el futuro del preso quedaba vinculado a su disposición para colaborar y a la de los miembros de su familia. Así, el radio de acción del sistema penal no quedó localizado en lo judicial, se extendió a todo el campo social de una política represiva que ocupó tanto el espacio público como el privado. La colaboración presentaba una serie de incentivos muy significativos del plan de reeducación social que diseñó el franquismo. El mensaje dirigido a los presos era claro: si trabajaba podría estar más cerca de la familia. La disciplina y la jerarquización militar implantaron la obediencia como la obligación primera. Su fusión con los principios religiosos, potenciaron al máximo un régimen penal basado en la entrega total. Esta fue sintetizada como norma en torno al trabajo, pero la búsqueda de colaboración del recluso alcanzaba todos los aspectos presentados como beneficios. En esencia, el que obedecía recibía la reducción proporcional de condena, se conmutaban dos días de condena por cada uno trabajado. La mejora de la suerte en esta primera fase era automática: más comida, más comunicaciones familiares, más correspondencia... la segunda o fase intermedia de la condena ya pasaba a régimen suavizado. Se iría del aislamiento total al progresivo contacto con la vida al aire libre en función de la sentencia que se le hubiera impuesto. Si esta era leve podría trabajar con obreros libres y pernoctar en prisión (algo que ocurrió en parte con los destacamentos penales) y si era grave, como sucedía en la mayoría, se establecían cuatro períodos de observación:

$1^{\circ}$ ) Talleres dentro del penal.

$2^{\circ}$ ) Grandes Obras.

$3^{\circ}$ ) Obras en destacamentos ya con población libre.

$4^{\circ}$ ) Solicitar la libertad condicional.

Un patronato, el de Redención de Penas por el Trabajo, organizó todo lo relativo al empleo de los presos como mano de obra abundante y barata, a través sobre todo de la red de beneficencia de la Iglesia, que funcionó como un engranaje perfecto de presión y control sobre las familias de presos. A continuación se reproduce la primera hoja de filiación que diseñó el Patronato de Redención de Penas por el Trabajo, para crear un fichero con los datos de los presos. 


\section{Modelo ficha de trabajo (fichero) que debe remitirse al patronato (20 de agosto de 1939)}

Debe ser confeccionada por el médico, el capellán y el maestro, valiéndose de sus cooperadores que pueden ser reclusos de confianza pero siempre bajo la responsabilidad y vigilancia de aquellos.

El capellán podrá valerse de esta ocasión (y de otras parecidas cuando surjan) para hablar a los presos y enterarse de sus necesidades familiares haciendo una discreta propaganda religiosa. Advertir al penado de las graves consecuencias de dar datos falsos.

1- Domicilio familiar (nombre de la persona a quien la junta local debe entregar el subsidio)

2- Condena. Años, procesado, detenido, expresando si se le concedió permiso para trabajar

3- Estudios que ha cursado

4- Casa última (de trabajo)

5- Confianza profesional. Hombre útil para el trabajo (director)

6- Moralidad (capellán)

7- Deformidad o defecto físico (médico)

8- Enfermedad

9- Diagnóstico especial necesario

Fuente: Archivo General de la Administración. Justicia, 36/13980

$\mathrm{Su}$ primer punto ya indica un objetivo claro: ejercer el control directo sobre las familias a través de las juntas locales del patronato. Estas se encargaban de entregar las 15 pesetas mensuales por hijo (menos los descuentos) a la familia del preso, siempre que la junta de disciplina de la prisión siguiera certificando que este trabajaba y mostraba buena conducta. A cambio, las juntas tutelaban directamente a todos los miembros de la familia y si cualquiera de ellos cometía un delito o daba señales de mal comportamiento, el preso perdía automáticamente todos los beneficios y rebajas de condena que hubiera acumulado hasta la fecha. La fórmula alcanzó su grado máximo en la tutela de los niños, muchos de los cuales fueron internados en orfanatos donde fueron entregados o vendidos a otras familias. La libertad vigilada terminaría siendo el elemento principal de censura y presión social de posguerra. Los Servicios de Vigilancia y Tutela se organizaron básicamente sobre las autoridades locales quienes emitían informes sobre la conducta moral, política y social de los que habían pasado por la cárcel o habían sido investigados por alguna jurisdicción especial. Una red que alcanzaba a la familia entera, que fue perfeccionándose y dotándose de más medios hasta su disolución en 1954. Los poderes locales se adaptaron sumamente bien a sus nuevas funciones, especialmente a la hora de emitir denuncias e informes de conducta. La novedad fue el poder que recibieron para decidir sobre el destino de los que salían en libertad vigilada, desde la manutención de su familia a la fijación de su residencia. En definitiva, quien terminaba valorando la peligrosidad del delincuente eran el alcalde, el jefe de Falange, el párroco o la guardia civil, aunque también podían participar otras destacadas personalidades de la vida local, como ricos propietarios o empresarios que «patrocinaban» a presos, y aquellos «elementos femeninos especialmente caritativos». Todos ellos formaron parte de estas comisiones encargadas de permitir que los rojos volvieran y se reintegraran en la vida local.
Además de denegar la libertad condicional, las autoridades locales podían ordenar prisión preventiva de cualquiera que hubiera pasado por prisión y en última instancia seguían teniendo la llave de la cancelación de las «medidas preventivas» necesarias para permitir al preso cualquier actividad laboral o simplemente renovar el carnet de conducir. En abril de 1948, Francisco Martínez González, un jornalero murciano condenado a 20 años por desempeñar el cargo de Jurado del Tribunal Popular de Cartagena, salía del Penal del Dueso, donde había redimido pena como "Auxiliar de Oficinas, en la Sección Contabilidad», según certificaba el subdirector de la prisión. Había mostrado buena conducta y superado la instrucción religiosa y elemental, como igualmente certificaba, Sor María Ferrer Fernández, superiora de las Hijas de la Caridad; por último, su familia seguía una conducta política y moral intachable como aseguraban el inspector secretario de policía y el Obispado de Cartagena. Francisco consiguió la libertad condicional sin destierro. Sin embargo, la Junta de Libertad Vigilada de Murcia consideró que «no procede acceder a la cancelación de antecedentes penales» y denegaba devolverle el permiso de conducir ni trasladarse de un lugar a otro sin notificarlo previamente, obligando a que su familia se trasladara a la capital murciana. $^{3}$

La denegación sistemática del retorno llegó a tener tal magnitud que el Ministerio de Justicia terminó por sustituir las denegaciones por destinos a 250 kilómetros del pueblo natal. El destierro podía poner fin así a una larga nómina de castigos pero de ningún modo suponía un punto y final. Durante la segunda mitad de los años 40, el grueso de la política represiva se había desplazado hacia el poder local, donde se ejercía la más dura de las medidas económicas: la ley del mercado negro. Una política así diseñada desembocaba forzosamente en la muerte civil de los afectados; los antecedentes penales, la inscripción en el registro de penados y rebeldes, los distintos ficheros de inhabilitación profesional y para desempeñar 
cargos públicos, la incautación de bienes, las multas, etc. hacían imposible volver a la vida anterior a la guerra. Desempeñar cualquier actividad económica, viajar, hasta solicitar el carnet de conducir, exigía el permiso de la autoridad local o gubernativa y eso podía dar lugar a una nueva investigación. Ninguno de los mecanismos de revisión de las condenas, civiles o penales, llegaron a articularse realmente hasta entrados los años 50 , pero para entonces el miedo había paralizado a una parte de la sociedad. Las presas y sus familias formaron parte de un colectivo especialmente vulnerable y expuesto a esta larga serie de mecanismos de coacción.

\section{EL CONTROL DE LOS PRESOS Y SUS FAMILIAS}

Para la mayoría de los vencidos, dentro o fuera de la cárcel, escapar a la omnipresencia del castigo, eran prácticamente imposible. Las instituciones totalitarias potencian el aislamiento y la incomunicación de forma simultánea a la privación de libertad como norma colectiva, sin embargo, aquellas instituciones basadas en un modelo religioso como en el caso español, utilizaron este y otros recursos como una forma de modificación de conducta, en general, para separar al individuo del resto del grupo (Nizet y Rigaux, 2006: 146). De ahí que cualquier excepción a esta norma deba ser tenida en cuenta como una importante huella de la necesidad del preso, y muy en especial del preso político que consideraba que no había cometido delito alguno, de mantenerse aferrado al mundo de los vivos, de vencer la incomunicación por encima del castigo Una urgencia apremiada por el tiempo de encierro muy distinta a la posterior necesidad de elaborar una memoria personal que, a pesar del tiempo transcurrido, mantiene la pulsión de expresar su inocencia, ordenar sus recuerdos y borrar las humillaciones sufridas (Karstedt, Loader y Strang, 2011).

Tras meses sin lavarse, sin cambiarse de ropa, trasladados en vagones de ganado, haciendo sus necesidades en público, durmiendo de pie o en el suelo en $20 \mathrm{~cm}$, sometidos a palizas alternativas durante el día y la noche..., muchos encontraban en la cárcel un primer refugio, un lugar seguro. Allí todo estaba organizado, los horarios, la comida, los espacios, las visitas y las propias organizaciones políticas. Habían escapado a la primera descarga, habían conseguido salir de las comisarías, los cines, las fábricas, los sótanos y otros lugares similares que hacían a veces de improvisados depósitos de hombres y mujeres. Comenzaba otro tipo de supervivencia, una nueva etapa, basada en la incertidumbre, en la espera de la sentencia que podía tardar de dos a tres años en llegar, en la monotonía de los actos brutales y de la vida pendiente de un hilo. La prisión de aquella época acababa con la personalidad de todo recluso $\mathrm{y}$, antes o después, quebraba su resistencia psíquica. La presencia de la muerte era un gran acelerador de este final del individuo (Foucault, 2003). El régimen penitenciario la exhibía a todas horas y en todas partes: de día en la enfermería, de noche agonizando en la celda, o en el paredón al amanecer. Tuberculosis, avitaminosis o derrame cerebral por impacto de arma de fuego, el destino era el mismo.
Sobrevivir era cumplir una serie de normas que marcaban las diferencias entre los que mandaban y los que obedecían a través de toda una serie de rutinas diarias: vestir el uniforme de preso común, cantar los himnos nacionales en formación, asistir a misa, confesar, colaborar... a cambio, el buen preso obtendría el derecho de recibir señales del exterior, de recibir visitas y cartas, abriendo un canal que controlaba en todo momento la administración de la prisión. El preso recobraba así la esperanza en la vida, pero cargaba con la culpa de situar a su familia en una situación extrema a causa de su cautiverio. Los diseñadores del sistema penitenciario franquista, potenciaron al máximo este sentimiento de culpabilidad para favorecer técnica y reglamentariamente la conversión de los prisioneros, sancionando la «colaboración activa» como único vehículo de rebaja de la condena. Oficialmente, todos lo cumplían, pero el grado de interiorización del mensaje de la redención sigue siendo muy difícil de precisar, especialmente en aquellas condiciones tan adversas y brutales que alcanzaban no solo al individuo, como se ha señalado, sino a toda la familia.

Los consejos de guerra eran el momento crucial en la vida del preso. Antes o después se desbordaba toda la presión acumulada durante años acrecentada por las necesidades que pasaban la mayor parte de las familias de los condenados. Todo proyecto de vida quedaba suspendido por las penas de muerte o largas condenas de 30 y 20 años. Fue el momento que eligieron muchos para suicidarse, la estación final del viaje, empujados también por los malos tratos que sufrían en las declaraciones y traslados a diligencias judiciales, ya que la mayoría estaban envueltos en más de un proceso judicial o sancionador. En 1943, un preso de Sevilla hizo llegar al juez la siguiente nota manifestando su intención de matarse a causa de los malos tratos a los que era sometido: «Pienso suicidarme muy pronto pero quiero conozca antes toda la verdad y vea que no soy merecedor de tanto martirio». En mayo de 1947, el Ministerio de Justicia reconocía finalmente que «estas salidas (a declarar o a los consejos de guerra) no son de satisfacción de los reclusos, pues en ellas temen ser objeto de maltrato o vejaciones, que aunque en muchos casos no se conformen, son suficientes a crear un ambiente de desconfianza y recelo, hasta producir un estado colectivo de protesta en un momento determinado».

Frente a esa imposibilidad de volver a su vida corriente, emergió con fuerza la rabia y la protesta, unas veces de forma individual y aislada, otras a través de plantes y fugas más o menos organizadas, pero sobre todo favoreció el fortalecimiento de la identidad de grupo, precisamente el objetivo al que estaba consagrada evitar la redención de penas. El conflicto alcanzó proporciones muy violentas desde un principio, pero no fue simplemente la prolongación de la guerra por otros medios. Las medidas disciplinarias fomentaban sobre todo la denigración corporal: aislamiento (celdas de castigo, sin luz, sin agua, donde el preso convivía con sus propias heces y llegaba a autolesionarse con las uñas de los pies), torturas (los malos tratos eran prácticas muy asentadas y difíciles de erradicar incluso por la propia dirección de prisiones), o nuevos cargos que incluso po- 
dían llevar a otro juicio militar por actividades políticas con resultado fatal. Se establecieron rebajas de condena y medidas de choque contra las denominadas actividades subversivas en prisión, fundamentalmente dictadas por el Coronel Eymar, y llevadas a cabo por la policía política que utilizaron a otros tantos presos como su brazo ejecutor dentro de las cárceles (Gómez Bravo y Marco, 2012). Estas medidas, sin embargo, no tuvieron el éxito que cosecharon en la calle donde habían sido seguidas por una escalada de denuncias. Un informe de abril de 1942 señalaba como «raro en esta clase de gente, reclusos políticos, la delación antes por el contrario, hasta los más torpes tienden a encubrirse. ${ }^{4} \gg$ Las autoridades decidieron aumentar la presión interna alertados por el giro que parecía tomar la guerra en Europa. El 2 de noviembre de 1943 fue interceptada una carta que salía del Fuerte de San Cristóbal, en Pamplona, que resumía una reunión entre dos presos políticos:

Me preguntó qué haríamos con ellos en caso de que esto... ¿me entiendes verdad? Pues le contesté que si dependiera de mí lo haría lo mismo que ellos, eliminar, o si no lo más cerca Méjico, el hombre se quedó paralizado y me preguntó si era cosa mía o de mis dirigentes y le dije que no teníamos dirigentes que ellos por ahora, que era un pensamiento propio, y me contestó que si los demás piensan así íbamos arreglados. ${ }^{5}$

El odio hacia sus captores y denunciantes, a los que desean un doloroso final, llegó a constituir una auténtica obsesión. La venganza se convirtió en una cuestión de honor familiar «muero con el convencimiento de que sabréis vengar mi muerte por el honor de la familia», porque el mayor dolor de todos ellos consistió en que los trataran como a criminales, vulgares ladrones y asesinos. Ni en sus cartas ni en sus memorias se resignaron nunca los presos políticos a ser tratados así, e intentaron siempre librar en lo posible de esa culpa a la familia. «¡No agachéis la cabeza, no he sido un criminal, no tenéis nada de lo que avergonzaros...!» repiten seguidamente tras expresar sus deseos de venganza. ${ }^{6}$

La familia, verdadero soporte de este ejército derrotado, sufría de distinta manera las numerosas cargas que generaba esta situación y que intenta disimular a toda costa. La económica, quitándose de comer en ocasiones para poder mandar paquetes, pero también la estigmatización social y el riesgo constante de ser detenidos en cualquier momento. Pero el preso advertía en las visitas esas señales del acoso del hambre, el miedo y la preocupación constantes de sus familiares, acrecentando de nuevo su culpabilidad. El hambre, sin duda, fue la realidad más persistente a ambos lados de las rejas. Si los presos no recibían nada del exterior se debilitaban, enfermaban y podían morir pero cuando recibían un paquete no dejaban de pensar «si no os lo habréis quitado vosotros de la boca para dármelo a mí», como en el caso anterior. La familia fue utilizada como el principal medio para desarticular la solidaridad de grupo en prisión; el empeoramiento de sus condiciones de vida, la pérdida de cualquier ayuda o incluso el destierro, eran amenazas reales que las autorida- des locales hacían llegar a las familias de los presos que no se sometían, como se ha señalado anteriormente.

La comunicación entre los presos y sus familiares emergía como una respuesta emocional inmediata a esta situación. Se convirtió en el canal de comunicación de una población criminalizada y perseguida de modo implacable, que no tenía otra vía de expresión ni de escape. Y esa vía que creían directa, segura, se fue adaptando, más o menos estratégicamente, al paso del tiempo y a las distintas etapas de la vida en prisión, pero por encima de todo tuvo una preocupación constante: los hijos. En las cartas a los niños, la voz personal consigue elevarse sobre cualquier censura, también la de las propias organizaciones políticas y establecer una conexión especial. También aquí las reacciones fueron dispares, y fueron desde el consuelo, los consejos prácticos, al odio visceral. Todos sintieron la necesidad de explicar por escrito a sus hijos quienes eran y qué había sucedido. «Educaos como hombres libres», repetía José Rodríguez desde la cárcel de Sevilla en 1951 a sus pequeños. ${ }^{7}$

Esta idea, educar como ellos lo harían, se repite en muchos escritos, como si de esta forma su sacrificio no hubiera sido en vano. Pero el paso del tiempo acrecentó el temor ante la amenaza de una dictadura que controlaba la educación de sus hijos. La frustración y la rabia por ver que eran aleccionados por los otros, los mismos que los tenían presos, llevó a dirigir en ocasiones cartas violentas, duras y recriminatorias a los propios niños. Antonia Díaz, presa de Amorebieta, repetía a su hija en abril de 1940, que sacara a su hermano del colegio religioso en que lo había metido la familia de su marido, fusilado al comienzo de la guerra, recriminando a la niña el envío de una foto:

¡No me enseñes esas gracias a mi Abelardín, con el Cristo en la mano y en nombre de Cristo se están haciendo millones de injusticias. Todo lo que tengas lo vendes, tus pendientes y los míos, lo que sea para mandarme dinero. Prohíbo terminantemente ir al colegio, y menos tan lejos, si no os quiere nadie os marcháis a Madrid y pedís limosna. ${ }^{8}$

Los hijos fueron, en muchos casos, la causa principal para aceptar la redención. Balbina Torres, presa política en Segovia, dejó al más pequeño de sus hijos con 18 meses y en quince años pudo verlo únicamente dos veces. Era razón suficiente para que limpiara y fregara el suelo de la prisión, e incluso asistiera a la escuela de las monjas, para acortar la condena. Por encima de lo que pensaran sus compañeras del partido, tenía que salir de la cárcel cuanto antes y estar con sus hijos. «De mi, querida, poco puedo decirte porque siempre es igual. Te acuestas, te levantas y trabajas para redimir para poder salir pronto y mi trabajo es de la limpieza de la casa, por un día nos dan otro a las de la guerra porque así cuando termine ésta empiezo a cumplir los 15 años de paz». Ni el tiempo ni la distancia consiguieron borrar la fuerza de ese vínculo, el mayor de todos. La cárcel y el exilio de padres e hijos, que en ocasiones apenas se conocían, mostraban una co- 
rrespondencia algo fría, llena de expresiones convencionales y tonos neutros, que solía terminar en profunda emoción. Cuando López Raimundo recibió 25 dólares de sus hijos en Guatemala lo celebró ¡como si hubieran sido 25.000 mil! La entrada de una nueva generación en prisión, la de los estudiantes universitarios que desafiaban al régimen, comenzó a invertir esta relación. A finales de los años 50, eran ya los hijos los que ingresaban en prisión y sus padres los que escribían preocupados a ellos y a sus amigos, a otros padres, o a cualquiera con influencia que pudiera ayudar a sus hijos a escapar de aquella situación. ${ }^{9}$

La presencia de los hijos fue vital y no sólo de manera simbólica en el apoyo familiar a los presos. Muchos de ellos se trasladaron a la ciudad donde cumplía condena el padre o la madre, convirtiéndose en el núcleo fundamental de la apuesta por la vida. Aquellos que carecieron de esta presencia o notaron que se debilitaba, acuciados por los gastos, la enfermedad y otros tantos problemas, podían caer durante días en un pesimismo feroz. Un estado de ánimo que los presos conocían como «entrar en barrena». El recuerdo, la frustración, la culpa, convertían la tristeza en un ensimismamiento profundo que les llevaba a no poder reprimir las lágrimas, y a contar, con frecuencia a las madres, que no era la primera vez que lloraban.

Perdone madre, es la segunda vez que esto me pasa... decía Máximo Bragado en 1940, y un año después Miguel Xambrot se lamentaba desde su celda en Valencia cuantas veces hubiera preferido que le hubiesen fusilado para dejar de sufrir. Sin duda el tono más dramático se establece en estos momentos, cuando la rutina carcelaria ya había desmontado pieza a pieza la ilusión de dejar pronto aquellas cuatro paredes. ${ }^{10}$

Los vínculos entre los presos y sus familias se estrechaban ante todas estas circunstancias, unos sintiéndose culpables y otros víctimas de una persecución que les unía en la desgracia por igual. Lo demás lo hicieron el hambre, las privaciones de todo tipo, y el duelo diferido por la muerte que les rodeaba por doquier y que rara vez expresaban en las cartas. La intensidad de la descripción variaba en función del destinatario. Por ejemplo, Máximo Bragado, escribe desde Celanova (Lugo) en septiembre del 40 a su madre pidiéndole cola de caballo para sus problemas digestivos y acto seguido, en otra carta, escribe a su hermano diciéndole que llevan cinco días sin comer. Las familias, por su parte, no sólo ocultaban a los presos las penurias materiales que pasaban; la mayoría de los presos nunca supo lo que costó su libertad condicional, que pagaron miles de mujeres con dinero prestado, lavando, planchando, haciendo la comida y asumiendo todo tipo de prestaciones personales y favores a funcionarios de prisiones, policías y militares sin escrúpulos que se aprovechaban de su situación. La nota detallada con las deudas que fue acumulando un jefe de servicios de la prisión de San Sebastián con la mujer de un preso ascendía a seis mil pesetas del año 1944. Se trasladó a Huelva y se olvidó de la libertad condicional de su marido. Otras veces, las propias presas cuando salían en libertad condicio- nal, eran acosadas sexualmente por los antiguos guardias que llegaron a escribirles reiteradas veces cartas donde manifestaban «estar con ansias. ${ }^{11} »$

A través de los distintos objetos que los presos pedían a sus familias y amigos es posible advertir la propia evolución de las prisiones en los primeros veinte años de posguerra. La comida, el tabaco, y los avales fueron las peticiones más demandadas al principio; a partir de 1946-1947 se necesitaba más el dinero para abogados (trámites, revisión, libertad condicional), las medicinas (a medida que el estado de salud se iba deteriorando) o los libros, que poco a poco iban siendo permitidos del exterior. A finales de los años 50 ya era posible iniciar estudios reglados, vinculados a la rebaja de condena, pero la mayoría solicitaban los libros con el mismo afán que la escritura: para mantenerse vivos y activos, como el caso de José Satué, vuelto a España del exilio para relanzar la UGT, que pedía a su hermano, desde el penal de Burgos en 1950, que le enviara libros que no fueran «ñoñeces». Pero por encima de todo y de forma invariable a lo largo del tiempo, todos pedían que les siguieran escribiendo, que no se olvidaran de ellos, «porque en estos lugares la correspondencia es media vida, y tú no querrás que muera, ¿verdad ? $^{12}$ 〉)

Ese era el destino, físico o moral, de los que dejaban de tener contacto con el exterior; entraban en barrena y no salían de ella, estaban muertos en vida, como muchos otros al lado de las rejas que se habían quedado solos completamente, sin importar ya a nadie. Una sensación que mayoritariamente experimentaban cuando salían al exterior, al volver a la calle y encontrarse completamente desamparados, sin recurso alguno, fuera del trabajo y vigilados constantemente, porque su mundo, tanto el anterior a la guerra como el de la cárcel, había desaparecido. Muchos de los amigos ya no estaban o no querían saber nada de ellos por su condición de presos políticos; situación que describe Juan Díaz a Amaro del Rosal. «Sancho tiene una buena colocación pero huye al hablar con él y se le ve a menudo en la Iglesia con su señora». Una ruptura que también se produjo en el interior de las prisiones, y que terminó excluyendo a aquellos que aceptaban colaborar con la dirección de prisiones para redimir pena. En abril de 1947, el dirigente comunista Emiliano Fábregas, informaba semanalmente a la dirección del Partido, sobre la conducta personal de algunos compañeros presos en la Modelo de Barcelona: «los de la procesión fueron: Benedicto, Zapatero, Vicens, Octavio, Serafín García, Rebenaque. Los que besaron la mano al cura, Vicens y Víctor Mora. $\left.{ }^{13}\right\rangle$

La masificación, la generalización del soborno, del contrabando y del estraperlo en un país defensor de la autarquía como seña de identidad, facilitó este tráfico de cartas y noticias que representaban en muchos casos el único contacto con la familia o los seres queridos. En este contexto generalizado, en el corazón del infierno, escribir o recibir una carta podía resultar vital, a veces el único antídoto ante el miedo y la ansiedad, el único rastro de humanidad en un mundo absolutamente agresivo y violento. Una noticia, una frase de aliento, un simple nombre 
en un trozo de papel, eran capaces de rescatar a alguno de aquellos de cientos de miles de condenados a una muerte segura, sobre todo por las condiciones generalizas del encierro hasta prácticamente finalizar los años 40. Muchos de ellos presos desde el comienzo de la guerra, sufrieron un sinfín de penalidades que quebrarían la resistencia física y moral del más distinguido héroe de nuestros días. Sin embargo, la mayoría han sido olvidados y han muerto sin recobrar la dignidad que su paso por la cárcel y su trato como criminales consiguieron arrebatarles (Todorov, 2009). En aquel proceso tuvieron, y de manera muy especial, un decisivo papel las familias. De ahí la importancia que la redención de penas, que hizo las veces de reglamento de prisiones al menos hasta 1948 , concediera a esa relación entre el preso y su familia. Un objetivo que nunca abandonaría del todo la política penitenciaria de la dictadura, a pesar de que, a medida que pasaba el tiempo y se alejaba la postguerra, como ha podido verse en algunos de los fragmentos de las cartas mostrados anteriormente, se iba desplazando lentamente hacia cuestiones meramente legales.

\section{NOTAS}

1 HAR2014-52065-P, Madrid en Guerra 1936-1948: Capital, frente, retaguardia, y ciudad en guerra.

2 Decreto 281, Salamanca, 28 de 5 de 1937, Declarando el derecho al trabajo como principio básico de los prisioneros según el punto 15 de Falange y de las JONS.

3 Archivo General de la Administración. Sección Justicia, Dirección General de Prisiones, 41/05060.

4 AGA 41/11937.

5 Carta de Felipe Elorza a Pello AGA 41/11965

6 Carta de despedida de Ramón Brufau. Cárcel de Lérida. 11 de septiembre de 1939. Archivo Histórico Partido Comunista de España 44/42.

7 AGA 44/12234

8 La censura y las anotaciones de esta carta fueron realizadas por la Madre Superiora de la cárcel de mujeres de Amorebieta, Simona Azpiroz, quien informó que Antonia trabajaba bien formando a las reclusas dada su calidad de maestra, pero últimamente, dado su nerviosismo la habían tenido que retirar, «hasta tal punto que algunas cartas de la citada reclusa han sido rotas sin enviarlas. La correspondencia de sus familiares es normal y breve observando el estado intelectual en que se encuentra ella Entre sus familiares figura un cuñado sacerdote. La cantidad de dinero recibido es muy escaso». La Superiora no cree necesaria sanción en cuanto a la deficiencia mental de la reclusa, típicamente izquierdista. «Se negó a que su cuñado sacerdote metiera a su hijo en un hospicio y de ahí las malas relaciones con la familia. Antonia Díaz fue detenida en Madrid el 29 de marzo de 1939 , condenada a 30 años». AGA 41/11951.

9 AGA 41/11432.

10 AGA 41/11324 y AGA 44/32456

11 Juzgado de Tarragona. AGA 41/11946.

12 AHPC 41/49.

13 Archivo Fundación Pablo Iglesias. AARD 265.

\section{BIBLIOGRAFÍA}

Álvarez Bolado, Alfonso (1995) Para ganar la guerra, para ganar la paz. Universidad Pontificia, Salamanca.

Casanova, Julián (2017) «Republic, Civil War and Dictatorship: the peculiarities of spanish history». Journal of Contemporary History, 52: 25-36.

Egido, Angeles y Eiroa, Matilde (2005) «Los campos de concentración franquistas en el contexto europeo». Ayer, 57: 81-112.

Foucault, Michel (2003) La vida de los hombres infames. Akal, Barcelona.

Gómez Bravo, Gutmaro (2009) El exilio interior. Cárcel y represión en la España franquista. Taurus, Madrid.

Gómez Bravo, Gutmaro (2017) Geografia Humana de la represión franquista. Del golpe a la Guerra de Ocupación (1936-1941). Cátedra, Madrid.

Gómez Bravo, Gutmaro y Marco, Jorge (2012) La obra del miedo. Violencia y control social en la España franquista. Península, Barcelona.

Karstedt, Sussane; Loader, Ian y Strang, Heather (2011) Emotions, crime and Justice. Hart Publising, Oxford.

Martin Torrent, Reverendo Padre (1946) «La religión en las prisiones». Revista de Estudios Penitenciarios, 3: 23-34.

Montero, Feliciano (2007) Cuestión religiosa y democracia republicana en España (1931-1939). Pamplona-UPNA, Pamplona.

Nizet, Jean y Rigaux, Natalie (2006) La sociologia de Ervin Goffman. Melusina, Barcelona.

Pérez del Pulgar, José Agustín (1939) La solución que España da al problema de los presos politicos. Librería Santarén, Valladolid.

Pla i Deniel, Enrique (1939) El triunfo de la Ciudad de Dios y la resurrección de España. El Mensajero del Corazón de Jesús, Bilbao.

Sánchez de Muniain, José María (1946) «Concepto y teoría de la propaganda». Arbor, 17: 205-246.

Sierra Blas, Verónica (2016) Cartas presas. La correspondencia carcelaria en la Guerra Civil y el franquismo. Marcial Pons, Madrid.

Todorov, Tvedan (2009) La experiencia totalitaria. Galaxia Gutemberg, Barcelona. 